\title{
Un pasado desde el presente. La historia y la política del tiempo en la justicia transicional*
}

Writing the Past out of the Present. History and the Politics of Time in Transitional Justice

Um passado desde o presente. A história e a política do tempo na justiça transicional

\section{Berber Bevernage $^{* *}$ (iD orcid.org/000-0002-3201-3119}

\author{
Traducción \\ Eugenia Gay, eugeniagay@gmail.com \\ Para citar: Bevernage, B. (2016). Un pasado desde el presente. La historia y la política del \\ tiempo en la justicia transicional. Revista Colombiana de Educación, (71), 25-51.
}

Recibido: 09/09/2015

* Traducción del inglés del artículo: Bevernage, B. (2010). Writing the past out of the present. History and the politics of time in transitional justice. History Workshop Journal, 69 (1), 111-131.

** Assistant Professor of historical theory at the Department of History at Ghent University (Belgium). His research focuses on the dissemination, attestation and contestation of historical discourse and historical culture in post-conflict situations. He has published in journals such as History and Theory, Memory Studies, Social History, History Workshop Journal and Rethinking History. Berber is (CO-)founder of the interdisciplinary research forum TAPAS/Thinking About the PASt' which focuses on popular, academic and artistic dealings with the past in a large variety of different cultural and social areas. Together with colleagues he established the 'International Network for Theory of History' which aims to foster collaboration and the exchange of ideas among theorists of history around the world.. 


\section{Resumen}

Una de las tendencias más notables de las últimas décadas en el campo de la justicia transicional -el ajuste de cuentas colectivo con los legados de violación de los derechos humanos después de dictaduras o conflictos violentos- es, sin duda, el auge de las llamadas "comisiones de la verdad". Con la creciente inversión política en comisiones de la verdad, y con la celebración de la verdad histórica a nivel mundial, la historia se ha trasladado al centro de la escena de la gestión ético-política del pasado colectivo. Sin embargo, este enfoque en la historia está lejos de ser una virtud obvia y plantea una pregunta simple pero importante: ¿por qué Estados que emergen de un periodo de violencia en los últimos tiempos han recurrido a la historia con el fin de alcanzar la unidad nacional y la reconciliación? La respuesta a esta pregunta, propondré, debe buscarse en la relación de la historia con una determinada "política del tiempo". En lugar de interpretar la política de transición en términos de una oposición entre el recuerdo y el olvido, como es costumbre, mostraré que el campo actual de la justicia transicional representa un espacio de disputa para dos maneras contrastantes de recordar que se fundamentan en características temporales opuestas. Las comisiones de la verdad no se apropian de cualquier clase de recuerdo al azar, sino que apelan específicamente a la historia o, más exactamente, a cierto discurso de la historia. Una vez introducido en el campo de la justicia transicional, este discurso de la historia tiende a entrar en conflicto con la memoria o, más exactamente, con cierto tipo de memoria. La historia, sostengo, se introduce en el campo de la justicia transicional no a pesar de una memoria ya superabundante, sino a causa de ella; y el conflicto entre ambas se centra en diferentes concepciones del tiempo y de la relación entre el pasado y el presente. Utilizaré ejemplos de la Comisión Sudafricana para la Verdad y Reconciliación y de la Comisión de la Verdad y la Reconciliación de Sierra Leona.

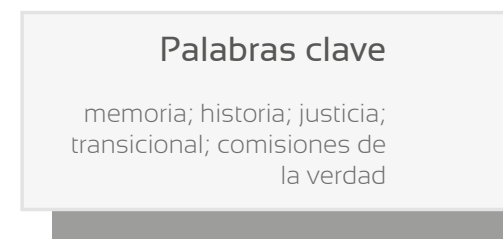

\section{Keywords}

memory; history justice; transitional; truth commissions

\begin{abstract}
One of the most remarkable trends of the past decades in the field of transitional justice is undoubtedly the rise of the so-called 'truth commissions'. With the increasing political investment in truth commissions, and with a worldwide celebration of historical truth, history has moved to centre stage in the ethico-political management of the past. However this focus on history is far from a self-evident virtue and raises a simple but important question why recently have states which have come out of a period of violence turned to history in order to attain national unity and reconciliation? The answer to this question, I argue, must be sought in history's relation to a specific 'politics of time'. Instead of interpreting transitional politics in terms of an opposition between remembering and forgetting, as is often done, I will show that the current field of transitional justice is an arena for two conflicting ways of remembering which are driven by contrary temporal features. Truth commissions do not appropriate any kind of remembrance, at random, but specifically turn to history, or, more accurately, to a certain discourse of history. Once introduced into the field of transitional justice, this discourse of history tends to conflict with memory, or, more accurately, with a certain kind of memory. History, I claim, is introduced into the field of transitional justice not despite an already overabundant memory but because of it; and the conflict between the two is centred on different conceptions of time and different conceptions of the relation between past and present. Throughout this paper we will use illustrations from the South African and Sierra Leonean Truth and Reconciliation Commissions.
\end{abstract}

\section{Resumo}

Uma das tendenciais mais notáveis das últimas décadas no campo da justiça transicional - o ajuste de contas coletivo com os legados de violação dos direitos humanos depois das ditaduras ou conflitos violentos- é, sim duvida, o crescimento das chamadas "comissões da verdade". Com a crescente inversão políticas em comissões da verdade, e com a celebração da verdade histórica ao nível mundial, a história se tem transferida ao centro da cena da gestão ético-política do passado coletivo. Porém, este enfoque na história está longe de ser uma virtude óbvia e coloca uma questão simples, mas importante: Por quê os Estados que emergem dum período de violência nos últimos tempos têm recorrido á história com o fim de conseguir a unidade nacional e a reconciliação? A resposta a esta pergunta, eu proponho, tem que procurar-se na relação da história com certa "política do tempo". Em lugar de interpretar a política de transição em termos duma oposição entre a lembrança e o esquecimento, como é costume, eu vou mostrar que o campo atual da justiça transicional representa um espaço de controvérsia para duas maneiras contrastantes de lembrar que se fundamentam em características temporais opostas. As comissões da verdade não se apropriam de qualquer de lembrança, mas são referidas mais exatamente á historia ou á certo discurso da história. Uma vez introduzido no campo da justiça transicional, este disN. ${ }^{\circ} 71$ curso da história tende á entrar em conflito com a memória ou, mais exatamente, com certo tipo de memória. A história, eu prendo, se introduze no campo da justiça transicional não apesar duma memória já superabundante, mas por causa dela; e o conflito entre as duas concentrando-se em diferentes concepções do tempo e da relação entre o passado e o presente Eu vou usar exemplos da Comissão Sul africana para a Verdade e Reconciliação e da Comissão da Verdade e Reconciliação do Serra Leoa.

\section{Palavras chave}

memória; história; justiça; transitório; comissões da verdade 
U na de las tendencias más notables de las últimas décadas en el campo de la justicia transicional -el ajuste de cuentas colectivo con los legados de violación de los derechos humanos después de dictaduras o conflictos violentos- es, sin duda, el auge de las Ilamadas "comisiones de la verdad": aquellos cuerpos semijudiciales que, en contraste con los tribunales penales o tribunales de guerra, no pueden sentenciar ni castigar, sino que ofrecen un "decir la verdad" oficialmente sancionado como fuente alternativa de justicia ${ }^{1}$. La innovación jurídica de estas comisiones de la verdad es, como se argumenta generalmente, que crean la posibilidad de abordar el doloroso pasado en situaciones en las que amnistías o restricciones políticas excluyen la posibilidad de un proceso penal. Los defensores de las comisiones de la verdad a menudo afirman que la revelación, el reconocimiento y el recuerdo de la verdad histórica en sí mismos constituyen una forma de justicia restaurativa, que representa una valiosa alternativa a la justicia retributiva "dura"2. La famosa "lucha de la memoria contra el olvido" (véase por ejemplo Truth and Reconciliation Commission -en adelante, TRC-, 1998a) de Milán Kundera, o la afirmación de George Santayana de que "los que olvidan el pasado están condenados a repetirlo" (véase por ejemplo Tutu, 1999), o la antigua creencia judía de que "recordar es el secreto de la redención" (véase por ejemplo Boraine, 2000), son sentimientos que pueden movilizarse como justificación para "decir la verdad". Es común escuchar que "decir la verdad" es en sí mismo productivo, como un factor importante para la obtención de la paz social y la restauración de la confianza ciudadana en naciones heridas, de una manera que nunca podría ser consumada por tribunales o purgas.

Desde las primeras experiencias de comisiones de la verdad en América Latina en la década de 1980, el fenómeno se ha producido en más de treinta países del mundo33. Por su parte, la divulgación de la "verdad históri$\mathrm{ca}^{\prime \prime}$ ha sido reconocida internacionalmente como un derecho inalienable ${ }^{4}$. En palabras del relator especial de la ONU, Louis Joinet (1999):

1 Un agradecimiento especial a Bouke Billiet, Maja Musi, Gita Deneckere, Jan Art y Chris Lorenz. La redacción de este artículo ha sido posible gracias al apoyo de la Research Foundation-Flandes. Para un estudio clásico sobre la amplia problemática de la justicia transicional, consultar Kritz (1995).

2 Para un análisis de los argumentos que se utilizan generalmente en defensa de las comisiones de la verdad, véase Dyzenhaus (2000) y Gutmann y Thompson (2000).

3 Para una visión general de las comisiones de la verdad más importantes a nivel internacional, véase Hayner (2001).

4 Esta filosofía jurídica fue iniciada en el caso Velásquez Rodríguez en Honduras por la Corte Interamericana de Derechos Humanos en 1988 y fue adoptada por la ONU a mediados de los años noventa. Para una discusión, véase Baets (2002).

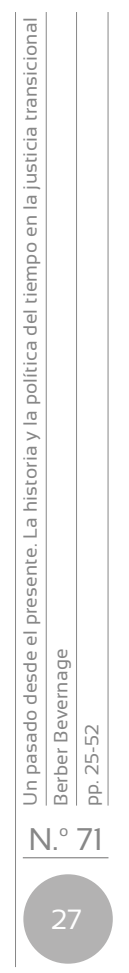


Su corolario es un "deber de recordar" por parte del Estado: deber de posicionarse contra las perversiones de la historia que llevan por nombre revisionismo o negacionismo, pues la historia de su opresión forma parte del patrimonio nacional de un pueblo y como tal debe ser preservado.

Con la creciente inversión política en comisiones de la verdad, y con la celebración de la verdad histórica a nivel mundial, la historia se ha trasladado al centro de la escena de la gestión ético-política del pasado colectivo.

Sin embargo, este giro hacia la historia, en el contexto de la resolución de conflictos y de la consolidación de la nación, está -sostengo- lejos de ser una virtud evidente. Si bien hay una larga tradición que conjuga la historiografía con la construcción nacional, esta historiografía en general ha conjurado un pasado antiguo y glorioso que articula una unidad mítica o un origen común. Cuando se aborda el fenómeno de las comisiones de la verdad, al contrario, se trata de un pasado repleto de atrocidades vergonzosas y divisoras.

En la mayoría de los casos, el aumento del establecimiento de comisiones de la verdad no se puede explicar exclusivamente por su capacidad de revelar los hechos. A menudo existen limitaciones jurídicas y políticas que impiden a las comisiones de la verdad nombrar a los perpetradores o cómplices, o realizar una descripción exhaustiva de los eventos en los que estaban involucrados. En consecuencia, las revelaciones de los informes oficiales de las comisiones pueden parecer insubstanciales en comparación con los datos registrados previamente en la prensa, en los libros y en otros lugares ${ }^{5}$. Dependiendo de la naturaleza del conflicto, la narración del pasado en los informes oficiales suele tomar la forma de una "articulación procesal de lo ya conocido" ${ }^{6}$, que hace poco más que reconocer oficialmente lo que podría denominarse "secretos públicos".

Además, las sociedades que tratan de desligarse de conflictos violentos y atrocidades masivas a menudo no muestran una falta de memoria sino, por el contrario, experimentan lo que Charles Maier (1993) ha denominado un "exceso de memoria", que continuamente amenaza con restaurar antiguos rencores. De acuerdo con Eric Doxtader (2001), por ejemplo, las negociaciones de paz de la década de 1990 en Sudáfrica solo tuvieron éxito porque los negociadores acordaron en primera instancia suspender temporalmente la memoria del conflicto. En contraste con su

5 La TRC sudafricana, por ejemplo, admitió que su informe contiene un menor número de nombres que la mayoría de los libros sobre el tema (TRC, 1998b).

6 Este término se toma de Soyinka (1999). Jose Zalaquett, abogado y miembro de la Comisión Nacional de la Verdad y la Reconciliación, comenta que la revelación de la verdad es especialmente importante en situaciones en las cuales los abusos permanecen ocultos o sin resolver. En el caso del apartheid, escribe, los abusos a menudo son bien conocidos, muy visibles y racionalizados en lugar de ser negados por el Estado. En tales casos, según él, el reconocimiento es más importante que la verdad (Boraine, Levy y Scheffer, 1997). 
posterior compromiso de "perdonar pero no olvidar", los negociadores definieron originalmente el concepto político de reconciliación en términos de amnistía y amnesia. Como señala Doxtader, el propio Nelson Mandela había definido inicialmente la reconciliación como un estado de cosas en el que las "injusticias y los agravios del pasado serían enterrados y olvidados y se forjaría un nuevo comienzo", y le tomó algunos años revisar esta opinión para reconciliarse con la idea de que el pasado no se podía dejar atrás (Nelson Mandela, citado en Doxtader, 2003) ${ }^{7}$.

Además, algunos comentaristas, incluidos muchos historiadores, argumentan que a menudo las comisiones de la verdad, en contraste con su retórica oficial, en realidad sufren de una memoria a corto plazo, lo que produce una amnesia social en lugar de forjar una memoria propiamente colectiva (Buncy, 2000; Grunebaum-Ralph, 2001). Verne Harris (2002), por ejemplo, sugiere que las comisiones de la verdad ofrecen "un guiño al recuerdo en beneficio de un olvido más profundo", mientras que Anthony Holiday (2000) sostiene que despliegan una "retórica amnésica", y Jacques Derrida, de modo semejante, se pregunta si lo que hacen no constituye potenciales "ejercicio[s] de olvido" (2002, p. 54). El giro hacia la historia, por lo tanto, difícilmente puede explicarse por la sola referencia al deseo de conservar los recuerdos del pasado. La metodología o la epistemología de la historiografía académica tampoco son de gran interés para las comisiones de la verdad. La mayoría de las veces se emplean metodologías alternativas, y en ocasiones el concepto de verdad se ha extendido para incluir verdades personales, sociales, curativas y de reparación que son generalmente ajenas a la historia profesional ${ }^{8}$.

Todo lo antedicho, por lo tanto, plantea una pregunta simple pero importante: ¿por qué Estados que emergen de un periodo de violencia en los últimos tiempos han recurrido a la historia con el fin de alcanzar la unidad nacional y la reconciliación? La respuesta a esta pregunta, propondré, debe

7 Refiriéndose en 1994 al discurso de Mandela, el historiador estadounidense Eric Foner advirtió a sus colegas sudafricanos que la política de reconciliación nacional podría resultar en un gran desafío para la profesión (Foner, 1995).

8 El informe de la trc de Sudáfrica, por ejemplo, identifica cuatro nociones ya famosas de verdad: la verdad de hecho, o forense; la verdad personal o narrativa; la verdad social, o "dialógica"; y la verdad restaurativa y curativa (1998a, pp. 110-114). Con la formulación de una verdad social, la Comisión subrayaba especialmente la importancia del proceso por el que se llegó a la verdad. Esta idea fue inspirada directamente por la distinción entre una "verdad de microscopio" y una "verdad del diálogo", que el juez constitucional y miembro de la anc, Albie Sachs, introdujo en los debates que precedieron a la Comisión (citado en Boraine y Levy, 1995). Sin embargo, nociones de verdad muy diferentes funcionan en diferentes comisiones de la verdad. Como sostiene Deborah Posel (2008), la reacción de las diferentes comisiones de la verdad a los desafíos epistemológicos planteados por el concepto de verdad varían, desde el recurso a un "objetivismo fundamentalista" (ella pone el ejemplo de la comisión de la verdad palestina), a una aceptación activa de lo subjetivo y una "versión reflexiva de decir la verdad, fruto de un examen de conciencia, librada de la arrogancia de la razón ilustrada" (p. 127). Además del caso de Sudáfrica, Posel da los ejemplos de las comisiones de la verdad de Sierra Leona y Marruecos.

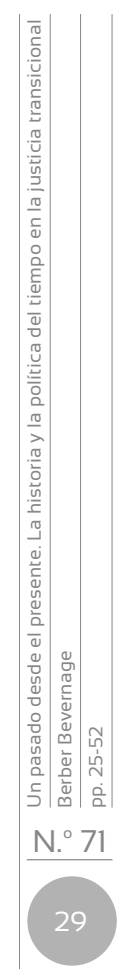


buscarse en la relación de la historia con una determinada "política del tiempo". En lugar de interpretar la política de transición en términos de una oposición entre el recuerdo y el olvido, como es costumbre (véase Minow, 1998), mostraré que el campo actual de la justicia transicional representa un espacio de disputa para dos maneras contrastantes de recordar que se fundamentan en características temporales opuestas ${ }^{9}$. Las comisiones de la verdad no se apropian de cualquier clase de recuerdo al azar, sino que apelan específicamente a la historia o, más exactamente, a cierto discurso de la historia. Una vez introducido en el campo de la justicia transicional, este discurso de la historia tiende a entrar en conflicto con la memoria o, más exactamente, con cierto tipo de memoria (Levi, 1989). La historia, sostengo, se introduce en el campo de la justicia transicional no a pesar de una memoria ya superabundante, sino a causa de ella; y el conflicto entre ambas se centra en diferentes concepciones del tiempo y de la relación entre el pasado y el presente.

Situar la memoria y la historia en el contexto de una política del tiempo nos permite captar la dimensión de la historia que excede sus funciones tradicionales de representar el pasado, buscar la verdad y generar significado: la de su performatividad. Con esto quiero decir que el lenguaje histórico no solo se utiliza para describir la realidad (el llamado uso "constatativo" del lenguaje), sino que también produce efectos sociopolíticos sustanciales y que en parte contribuye al estado de cosas que supone meramente describir (el Ilamado uso "performativo" del lenguaje ${ }^{10}$. Con el fin de explicar las dimensiones performativas de la historia tomaré prestadas algunas ideas del filósofo estadounidense Preston King. Utilizaré ejemplos de la Comisión Sudafricana para la Verdad y Reconciliación (TRC, por sus siglas en inglés), que fue establecida para registrar los crímenes del apartheid poco después de las primeras elecciones democráticas en 1994, y de la Comisión de la Verdad y la Reconciliación de Sierra Leona (SLTRC, por sus siglas en inglés), que comenzó a trabajar en 2002, después de once años de sangriento conflicto. En primer lugar, sin embargo, permítanme explicar qué es exactamente lo que tengo en mente cuando hablo de "historia" y "memoria" y por qué se oponen entre sí en términos temporales.

9 Utilizaré el término recordar como concepto "neutral" que se refiere a la "memoria" y a la "historia" como diferentes maneras de tratar con el pasado, en contraste con la amnesia.

10 Esta distinción entre el lenguaje constatativo y performativo fue introducida por primera vez en la filosofía del lenguaje por el filósofo británico J. L. Austin (1962), quien atacó el enfoque tradicional del lenguaje, que proponía que el uso dominante de los enunciados lingüísticos es el de realizar afirmaciones sobre la verdad o falsedad de los hechos. Austin exigió atención a un segundo tipo de forma lingüística: el enunciado performativo, que se utiliza para realizar una acción. Este tipo de enunciado no describe una realidad independiente de sí misma, sino que más bien produce activamente esa realidad. Austin ofrece una serie de ejemplos, que incluyen expresiones verbales tales como "Pido disculpas", "les doy la bienvenida", o "nombro este buque Liberté". 


\section{El discurso histórico moderno, la memoria del crimen y la modernidad "frágil"}

Cuando digo que las comisiones de la verdad recurren a la historia, me refiero a una determinada aproximación a la historia: un enfoque que quisiera llamar "discurso histórico moderno". El término modernidad se utiliza aquí para referirse a una visión del mundo, experiencia o conjunto de mentalidades específica, en lugar de delimitar una época en particular o un periodo histórico ${ }^{11}$. Hablar de un discurso histórico moderno en este sentido cualitativo (en lugar de cronológico) puede parecer extraño a primera vista. El crítico literario nacido de origen belga Paul de Man, por ejemplo, una vez declaró que "entre los diversos antónimos que vienen a la mente como posibles opuestos para 'modernidad' [...] ninguno es más productivo que el de 'historia'" (1983, p. 144). De Man describe la modernidad como marcada por el afán de renovación radical y la obsesión con una tabula rasa, o incluso con un olvido sistemático. Según él, la modernidad debe concebirse como "un deseo de acabar con cualquier cosa que hubiera antes, con la esperanza de llegar finalmente a un punto que pudiera llamarse un verdadero presente, un punto de origen que marcase un nuevo punto de partida" (p. 148).

En el campo de la estética, el significado original de la modernidad se refiere de hecho a las creaciones artísticas que rompieron con cualquier conexión con el pasado o la tradición. Cuando en 1863 el poeta Charles Baudelaire utilizó por primera vez la palabra modernité, en su ensayo Le Peintre de la vie moderne, lo asociaba con lo verdaderamente nuevo, la novedad efímera del presente en la que el artista moderno debía centrarse, disociándolo de la sobrevaloración de lo eterno y lo antiguamente evidente en la estética clásica (Frisby, 1985). Una comprensión similar de la experiencia social moderna como una ruptura con el pasado continuamente recapitulada, e inclinada hacia una orientación sociocultural sobre el futuro o lo nuevo, ha sido la característica de la obra de Jürgen Habermas. El término modernidad, declara llanamente, "expresa la convicción de que el futuro ya ha comenzado: Es la época que vive para el futuro, que se abre a la novedad del futuro" (Habermas, 1987, p. 5).

De este modo, la experiencia moderna, con su amor por el futuro y su rechazo de lo viejo parece más un opuesto de la historia que un candidato adecuado para caracterizar un discurso histórico. Sin embargo, el historiador intelectual Reinhart Koselleck (2004) ha argumentado convincentemente que la moderna "apertura" del futuro y la idea relacionada de "progreso" han sido de vital importancia en la génesis de los conceptos

11 Para una importante crítica del concepto de modernidad en general, y de sus características eurocéntricas en particular, véase Cooper (2005).

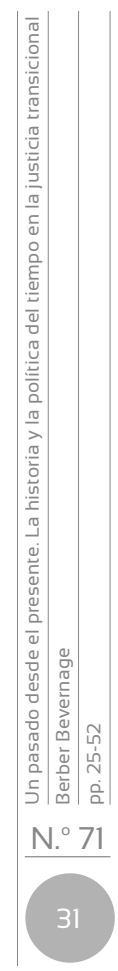


occidentales dominantes de la historia. Para Koselleck, la modernidad [Neuzeit] debe ser entendida principalmente como una experiencia radicalmente nueva de la historicidad y del tiempo, literalmente, un "tiempo nuevo" [neue Zeit]. Alrededor de la segunda mitad del siglo xVIII, sostiene Koselleck, las innovaciones tecnológicas y los efectos de lo que más tarde sería llamado "progreso" dieron lugar a una relación profundamente discontinua entre la memoria del pasado de las personas y sus esperanzas proyectadas hacia el futuro. $\mathrm{O}$, para ponerlo en los términos más abstractos de Koselleck, se produjo una ruptura entre el "espacio de experiencia" [Erfahrungsraum] y el "horizonte de expectativas" [Erwartungshorizont]. Hasta principios del siglo XVIII, afirma, las expectativas de la gente acerca del futuro y sus experiencias del pasado estaban estrechamente entrelazadas, de manera que el futuro solo podía imaginarse como una continuación del pasado experimentado ${ }^{12}$. Durante el periodo siguiente, en cambio, se llevó a cabo una ruptura cada vez mayor entre la experiencia y la expectativa, lo que llevó a una percepción generalizada de aceleración histórica que Koselleck describe como la temporalización [Verzeitlichung] de la historia (2004). El autor sugiere que durante este periodo el tiempo ganó una cualidad propiamente histórica. Ya no es simplemente el medio en el que ocurren todas las historias. A partir de entonces la historia ya no se produce en el tiempo, sino a través de él: "El tiempo se convierte en una fuerza dinámica e histórica por derecho propio" (p. 236).

El inicio de la modernidad también tuvo efectos significativos sobre el modo en que se imagina el pasado mismo ${ }^{13}$. Por un lado, Koselleck demuestra que la llegada de expectativas radicalmente nuevas sobre el futuro resultó en un cambio de valencia del estudio del pasado. El estudio del pasado ya no podía legitimarse convincentemente como fuente de lecciones vitales para la vida presente o futura, lo que provocó que la alguna vez influyente perspectiva de la Historia magistra vitae [la historia maestra de la vida] se disolviese lentamente. Por otra parte, fue precisamente el

12 Por supuesto, admite Koselleck, no puede decirse que esto ocurra para todos los estratos de la sociedad de la misma manera: en el mundo de la política y en el mundo intelectual, ciertos acontecimientos (las Cruzadas, el descubrimiento del Nuevo Mundo, la revolución copernicana, entre otros) separaron el espacio experiencial existente y crearon nuevas expectativas mucho antes de la segunda mitad del siglo xvIII.

13 Desde luego, se puede dudar de si el desarrollo de cosas tan importantes como los modernos conceptos de tiempo y de historia pueden datarse claramente en una década como afirma Koselleck, y podría ser más seguro tomar las fechas mencionadas como fundamentalmente simbólicas o elegir una delimitación cronológica menos precisa, como lo hace Lynn Hunt (2008), quien establece que un nuevo concepto de tiempo se afianzó en etapas sucesivas entre finales del siglo xvı y mediados del xIx. Sin embargo, la idea de Reinhart Koselleck de un Sattelzeit, o un punto de inflexión, a partir de mediados del siglo XVIII hasta mediados del siglo xIX (cuando las concepciones de tiempo e historia cambiaron radicalmente) encuentra confirmación en el trabajo más reciente de otros pensadores importantes. Véanse, por ejemplo, Hartog (2003) y Fritzsche (2004). 
"descubrimiento" del progreso lo que trajo consigo el "descubrimiento" del mundo histórico:

Las visiones histórica y progresiva del mundo tienen un origen común. Se complementan entre sí como rostros de Jano. Si el tiempo nuevo está ofreciendo algo nuevo todo el tiempo, el pasado diferente debe ser descubierto y reconocido, es decir, es su extrañeza lo que aumenta con el paso de los años (Koselleck, 2002).

La idea misma de la historia como un proceso unificado o un objeto epistemológico unificado solo germinó después de que la idea de progreso abriera el futuro y las personas pasaran a creer que podían "hacer" historia. Evidentemente, el "descubrimiento" del mundo histórico tuvo importantes consecuencias para la formación de la historiografía académica. De hecho, fue solo a partir de la separación cualitativa del pasado del presente y el futuro, que la historia pudo entenderse como una ciencia ${ }^{14}$. Lo que tengo en mente cuando utilizo la expresión "discurso histórico moderno" es esta dependencia fundamental por parte del concepto occidental dominante de la historia del énfasis modernista en el progreso, en la ruptura cualitativa entre pasado, presente y futuro, y en el concepto modernista de un tiempo que se convierte en una "fuerza histórica por derecho propio".

Volvamos por un momento a Habermas y a una observación importante acerca de la conciencia modernista de tiempo. Debido a la orientación radical de la modernidad hacia el futuro y su voluntad incansable para propulsar "el periodo más reciente [neuesten] de la era moderna [neue]" (1987, p. 7), Habermas afirma que la conciencia del tiempo de la modernidad y su autodefinición como una época autónoma es de hecho bastante lábil, por lo cual necesita renovar constantemente su autoconfianza. La mentalidad moderna no solo se repliega sobre sobre sí misma en sentido normativo, en la medida en que se niega a tomar sus orientaciones normativas de cualquier modelo suministrado por otras épocas, sino que también debe renovar continuamente la ruptura con el pasado. Citando a Hans Blumenberg, Habermas señala que la pretensión de la modernidad de ser capaz de lograr esta ruptura radical incesantemente es una ilusión, porque entra en conflicto con la realidad de la historia, en la que uno nunca puede comenzar con una pizarra limpia.

Muchos eventos históricos de diferentes clases pueden amenazar la conciencia moderna del tiempo. El creciente escepticismo acerca de las posibilidades de progreso, así como la profundización de la "conciencia

14 Koselleck no está solo en subrayar esta dependencia de la escritura moderna de la historia de la experiencia de una discontinuidad histórica. Michel de Certeau (1988), por ejemplo, también ha señalado que la historiografía occidental moderna solo pasó a existir con la efectivización de la diferenciación moderna entre presente y pasado, con la cual un pasado objetivado podría estudiarse desde el punto de vista de un presente autónomo.

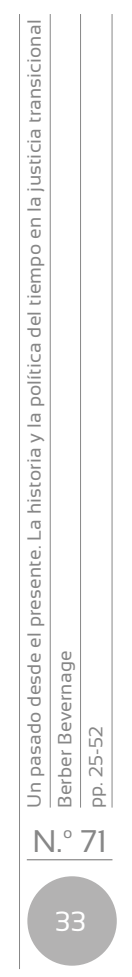


sobre las catástrofes de origen humano", son determinantes en este sentido (Torpey, 2006, p. 19). Pero al mismo tiempo, también debe considerarse como factor importante la presencia de la memoria, o más exactamente de un cierto tipo de memoria que, tomando prestado un término de Primo Levi (1989), describiré como "la memoria de los ultrajes". Levi la describe como un recuerdo de "las experiencias extremas, de las injurias sufridas o infligidas". Afirma que no se trata solo de una cuestión de recordar experiencias traumáticas del pasado, sino más bien de que la memoria puede ser traumática en sí misma, pues puede seguir siendo dolorosa o perturbadora, incluso después de varias décadas.

Este tipo de memoria puede oscurecer la línea divisoria entre el pasado y el presente que, como acabamos de ver, se encuentra en la raíz misma de la conciencia moderna del tiempo y la historiografía académica moderna. Por ejemplo, Gabrielle Spiegel (2002) afirma que la memoria judía post-Holocausto entra en conflicto con la empresa moderna de la historiografía precisamente porque reencarna, resucita, recicla el pasado, y al hacerlo, se niega a mantener el pasado en el pasado. En la misma línea, Lawrence Langer ha afirmado que la memoria de las atrocidades tiende a desarrollar un "tiempo duracional" que perturba el tiempo cronológico (1995).

Cuando actúan como fuerza social, las "memorias de los ultrajes" de hecho pueden reformular las concepciones de tiempo, de manera que este ya no se conceptualice como un "medio de cambio", y el paso del tiempo ya no asegure una "distancia" entre el pasado y el presente (Gumbrecht, 2006). En los últimos tiempos hemos podido observar este fenómeno en muchas situaciones diferentes. La influencia de grupos de víctimas organizados y altamente visibles y "emprendedores de la memoria", por ejemplo, a menudo da lugar a una experiencia que acentúa la proximidad del pasado $^{15}$. Como observa un comentarista,

aproximadamente desde el final de la Guerra Fría la distancia que normalmente nos separa del pasado ha sido fuertemente cuestionada en favor de una insistencia en que el pasado se encuentra constante y urgentemente presente como parte de nuestra experiencia cotidiana (Torpey, 2006, p. 19).

La difusión de expresiones que se refieren a la naturaleza fantasmal o extraordinaria del pasado -por ejemplo, se habla del "pasado acechante" (Rousso, 2002), o de "fantasmas en la mesa de la democracia" (Christie y Cribb, 2003)- también parece subrayar el sentimiento generalizado de

15 Según Bain Attwood, la noción de una distancia temporal que separa el pasado y el presente -un "distanciamiento histórico" en sus palabras- no es solo cuestionada por la memoria traumática, sino en varios aspectos también por la difusión de la práctica de la historia oral (2008, p. 80). 
una incómoda "presencia". Así mismo, los defensores de las políticas de reparación a menudo insisten en la persistencia obstinada de las injusticias históricas. Wole Soyinka, el nigeriano ganador del Premio Nobel de Literatura, por ejemplo, sustenta sus bien conocidos reclamos de reparación para el comercio transatlántico de esclavos a través de una lectura del pasado africano como una "continuidad diabólica" en la que las antiguas empalizadas de esclavos parecen nunca desaparecer (1999, p. 20).

Propongo entonces que el peculiar giro hacia el discurso histórico moderno en el campo de la justicia transicional debe situarse precisamente en este contexto ambiguo de una "modernidad lábil" y una creencia endeble en la posibilidad de una ruptura radical entre el pasado y el presente. Con base en lo que hemos Ilamado el discurso histórico moderno, sugiero, las comisiones de la verdad tienen por objeto la restauración o creación de una conciencia moderna del tiempo, que confirme una disyunción característicamente modernista entre pasado y presente. A su vez, esta idea del tiempo es profundamente cuestionada por las "memorias de los ultrajes", que se niegan a dejar pasar el pasado, y que insisten en que el pasado "acecha" cotidianamente al presente. Aunque creo que la emergencia internacional de comisiones de la verdad resulta de un reconocimiento implícito -a veces incluso explícito- del problema del "pasado acechante", sostengo que estas comisiones recurren al discurso histórico moderno precisamente porque se niegan a la idea de la "presencia" o "persistencia" del pasado (Bevernage, 2008) ${ }^{16}$. Esta me parece ser la paradoja principal que subyace al fenómeno contemporáneo de las comisiones de la verdad organizadas por el Estado.

\section{Las comisiones de la verdad en Sudáfrica y Sierra Leona}

La genealogía de la justicia transicional moderna, según Ruti Teitel, se remonta a los intentos de ordenar la justicia retributiva y de restablecer el Estado de derecho en las postrimerías de la Primera Guerra Mundial, y ciertamente de la Segunda. Pero su fase más reciente, caracterizada por la instalación de comisiones de la verdad, está sobre todo comprometida con la construcción nacional y tiene como objetivo preservar la paz social y crear una nueva comunidad política y civil (Teitel, 2003). Este fue sin duda el caso de la Comisión de la Verdad y la Reconciliación en Sudáfrica, cuyas raíces se encontraban indirectamente en los protocolos

16 Para una discusión detallada del escepticismo del discurso histórico moderno acerca de la "presencia" o "persistencia" del pasado, véase Bevernage (2008). Téngase en cuenta que en el momento en que escribí este artículo todavía tenía una visión ligeramente diferente acerca de la relación entre las comisiones de la verdad y el discurso de la historia. 
de la Constitución provisional de Sudáfrica de 1993, la cual establecía que la reconstrucción y la reconciliación nacionales habían creado la necesidad de comprensión y reparación, en lugar de venganza, represalias o victimización. Significativamente, se estableció formalmente en 1995 mediante una iniciativa parlamentaria denominada "Ley de Promoción de la Reconciliación y Unidad Nacional".

El cuerpo, conformado por diecisiete miembros, fue presidido por el arzobispo anglicano Desmond Tutu y tuvo uno de los mandatos más extensos para una comisión de la verdad hasta la fecha, con el fin de investigar las violaciones de los derechos humanos durante la época del apartheid, entre 1960 y 1994. Subdividido en tres comités interrelacionados (el Comité de Violaciones a los Derechos Humanos, el Comité de Reparaciones y Rehabilitación y el Comité de Amnistía), se ocupó tanto de los testimonios de las víctimas como de la necesidad de reparaciones. Polémicamente, también le había sido conferido el derecho de conceder amnistías individuales a los perpetradores de crímenes motivados políticamente. En 1998, después de reunir casi 23.000 testimonios de víctimas y testigos, y de recibir más de 7000 solicitudes de amnistía por parte de perpetradores, la Comisión publicó un informe final de cinco volúmenes y más tarde, en 2002 y 2003, añadió otros dos. Tanto en las diversas comunicaciones de la TRC lo largo de su periodo de trabajo activo -durante el cual recibieron una intensa cobertura de los medios de comunicacióny en su informe final, la Comisión extendió la conocida idea de la "nación arco iris", de Desmond Tutu, basada en el reconocimiento del valor de la reconciliación, y en la noción bantú de Ubuntu.

Al menos en la misma medida en que para el caso de Sudáfrica, los objetivos de paz social y construcción de la nación eran centrales para la Comisión de la Verdad y la Reconciliación de Sierra Leona (SLTRC). La iniciativa para la creación de la SLTRC fue tomada ya durante las negociaciones de paz de Lomé en 1999, aunque un resurgimiento de las hostilidades en 2000 retrasó considerablemente su comienzo. Hubo que esperar hasta 2002 antes de que la Comisión de hecho comenzara a trabajar, y se mantuvo activa hasta 2004 (O'Flaherty, 2004) $)^{17}$. La SLTRC se apoyó en gran medida en el ejemplo de su predecesor sudafricano. Al igual que la TRC, esta se basó en testimonios públicos de víctimas y perpetradores. También fue presidida por un líder religioso, el obispo metodista Joseph Humper, y estaba impregnada de un lenguaje de inspiración religiosa, que hablaba en

17 La prioridad de la doble meta de la paz social y la creación de comunidad política sobre el refuerzo del Estado de derecho está claramente ilustrada por el hecho de que las organizaciones de la sociedad civil y grupos de víctimas habían presionado originalmente por el establecimiento de una "Comisión de la Verdad, la Justicia y la Reconciliación", y se ofuscaron cuando el término "justicia" desapareció del nombre oficial de la Comisión (O'Flaherty, 2004, p. 54). 
términos de la necesidad de perdón, catarsis y sanación. Sin embargo, el caso de Sierra Leona se diferenció del de Sudáfrica en aspectos importantes. En primer lugar, la SLTRC no era totalmente nacional: desde un principio la onU desempeñó un papel importante en su creación, y el equipo de delegados, además de los cuatro ciudadanos de Sierra Leona nombrados por el presidente, también incluía tres miembros internacionales seleccionados por el Comisionado de las Naciones Unidas para los Derechos Humanos (SLTRC, 2004, p. 53). En segundo lugar, la sLTRC no podía ofrecer amnistía a los perpetradores a cambio de una revelación completa de la verdad, ya que el acuerdo de paz de Lomé ya había incluido una amnistía general para todos los partidos. Además, el sıTRC se encontró en la situación singular, y problemática, de tener que trabajar codo a codo con el Tribunal Especial para Sierra Leona, un Consejo de Guerra establecido por la ONU después de la ruptura del acuerdo de paz por parte de los rebeldes que había creado la posibilidad jurídica de que las amnistías fueran anuladas. Estas dos últimas características dificultaron a los comisionados de la SLTRC la reivindicación de que la narración pública del pasado histórico por sí misma constituía una forma de justicia de pleno derecho. Esto, sin embargo, llevó a los comisionados de Sierra Leona a afirmar los efectos terapéuticos y de reconciliación de decir la verdad con mayor convicción aún que sus colegas sudafricanos.

Una vez que comenzó a funcionar, la SLTRC dividió su trabajo en una serie de tres fases. Durante la primera, se recogieron más de 8000 testimonios de víctimas, testigos y perpetradores. Una segunda fase se dedicó casi por completo a la organización de una serie de audiencias (en su mayoría públicas). Después de las audiencias finales, la Comisión elaboró sus informes: inicialmente previsto para demorar unos cuatro meses, finalmente el trabajo llevó más de un año. El 5 de octubre de 2004 la Comisión presentó su informe al presidente ${ }^{18}$.

\section{Comisiones de la verdad: la voluntad de modernidad}

John Torpey afirma que la reciente "fiebre" mundial de reparaciones y disculpas ha suplantado en gran medida la elaboración de visiones de futuro en la política contemporánea. La preocupación por "hacer las paces con el pasado", reclama, es tan penetrante que el tradicional grito de guerra -"No hagas duelo, organiza"- del laborismo militante histórico ha sido sustituido por el dictum "Organiza para hacer duelo" (Torpey, 2003, p. 1). Si bien esta tesis se podría aplicar a determinadas ramas de

18 Sin embargo, debido a la mala labor de los editores, el informe estaba plagado de errores tipográficos, entre otros, y por lo tanto tuvo que ser reimpreso antes de que encontrara finalmente su camino hasta la audiencia nacional e internacional bien entrado el año 2005 (Hayner, 2007, p. 27).

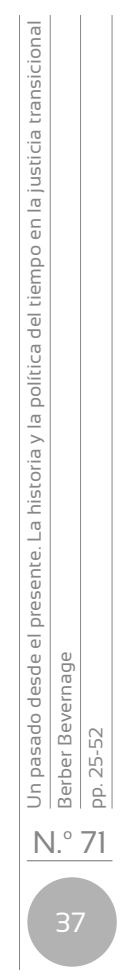


la política de reparación, sin duda no se sostiene para la justicia transicional en Sudáfrica o en Sierra Leona. El establecimiento de comisiones de la verdad en estos países no debe interpretarse como una obsesión con el pasado o una pérdida de interés en el futuro, sino más bien como síntoma de una creciente ansiedad respecto de las fallas del progreso y de la ruptura de la conciencia moderna del tiempo. De hecho, en muchos países que se recuperan de un periodo de conflicto violento, una parte significativa de las élites sociales y de la población urbana manifiesta una pronunciada "voluntad de modernidad", en el sentido de un manifiesto deseo de lo "nuevo", de una ruptura radical entre el pasado y el presente, e incluso del tipo de "olvido" que he descrito.

En Sudáfrica, por ejemplo, la dirección del Congreso Nacional Africano (ANC por sus siglas en inglés) tenía claro que quería que la TCR liberara al nuevo gobierno democrático de la carga del pasado concluyendo sus trabajos lo antes posible, "para que así de hecho dejemos estar al pasado y permitamos que la nación perdone un pasado que, sin embargo, no se atreve a olvidar" (Mbeki, 1996). Si el nuevo gobierno de Sudáfrica optó por una comisión de la verdad, fue motivado principalmente por el temor de que, sin esa comisión, no tendría éxito en romper con el pasado y este sería una enorme carga para la nación en su camino hacia el futuro. De hecho, poco después del inicio de las negociaciones de paz, Kader Asmal (el padre intelectual de la TRC) sostuvo que no se debía subestimar hasta qué punto el pasado seguía siendo una parte del presente y cómo podría sobrevivir como un intruso en el futuro. Negar el pasado sería correr el riesgo de tolerarlo como un "conductor fantasma en un viaje supuestamente nuevo" (Asmal, K.; Asmal, L. y Suresh Roberts, 1996, p. 71). Por lo tanto, Asmal evocaba la idea de una inundación constructiva o depuradora y comparaba la función de la TRC con la del corto pero poderoso "estallido catártico de una represa" que se lleva lo viejo y hace espacio para lo nuevo (p. 208).

Un anhelo de "progreso" similar fue expresado sin ambigüedades por el influyente teórico constitucional Albie Sachs:

[Si] hay una sensación de movimiento hacia adelante y hacia la creación de una nación y de una dignidad verdadera y compartida en este país, entonces creo que la presión para simplemente castigar, penalizar y crear comisiones de la verdad se hace mucho más leve (Citado en Boraine, Levy y Scheffer, 1997, p. 24).

El mensaje fue bien entendido por los comisionados de la TRC: en modo defensivo, anticiparon posibles críticas al afirmar que la Comisión no estaba obsesionada con el pasado, sino que trataba de lidiar con él solo por el bien del futuro (TRC, 1998a). Una vez que se hubiera "mirado la bestia del pasado a los ojos", afirma Desmond Tutu en su prólogo al 
informe final de la TRC, la puerta del pasado debía ser cerrada para no encarcelar al "glorioso futuro" (p. 22).

La ambición de ser más modernos y "mover el país hacia delante", lejos de su "oscuro pasado" fue también proclamada a viva voz por las élites políticas, culturales y religiosas de Sierra Leona, y esta ambición fue compartida con entusiasmo por la mayoría de los propios comisionados. Lejos de "eclipsar los modos visionarios de imaginar el futuro", la SLTRC Combinó su mirada retrospectiva con un gran anhelo de progreso. Según lo expresara el presidente de la SLTRC, la Comisión trataba "sobre nuevos comienzos" y sobre la "construcción de una nueva Sierra Leona" (Humper, s. f.). Esto fue particularmente claro, por ejemplo, en el proyecto futurista Ilamado "Visión Nacional para Sierra Leona", que fuera organizado por la SLTRC y que invitaba a la población a imaginar una "hoja de ruta" hacia el futuro. El proyecto fue diseñado para promover y legitimar la agenda ético-política de la propia Comisión, y este programa se refleja claramente en la pequeña selección de contribuciones que se reproducen en su Informe final. Todas las contribuciones seleccionadas Ilevan mensajes esperanzadores, como "Es verdad que la guerra ha terminado. Bienvenidos a la nueva Sierra Leona", "Mi Sierra Leona, un nuevo capítulo y una nueva era", o "Ahora es el momento de avanzar". Además, el proyecto produjo uno de los lemas centrales de la Comisión: "La inspiración es corramos, si no podemos correr, marchemos, si no podemos marchar, caminemos, si tampoco podemos caminar, entonces reptemos, pero de cualquier manera posible mantengámonos en movimiento" (SLTRC, 2004).

Este énfasis en la necesidad de progreso y modernidad torna problemática la cuestión de la "memoria" frente al "olvido". Si bien la Comisión envió un mensaje claro sobre la necesidad de "perdonar pero no olvidar", y de las capacidades curativas de recordar, su abordaje efectivo de estos problemas fue mucho más ambiguo, sobre todo cuando comparamos los anales oficiales de la Comisión con las transcripciones sin editar de las audiencias de las víctimas y los perpetradores ${ }^{19}$. Estas transcripciones muestran que un número considerable de víctimas y victimarios concebía que la verdadera misión de la SLTRC era la búsqueda del "perdón y el olvido". De manera sorpresiva, la respuesta de los comisionados a esta percepción cambió notablemente a lo largo de las audiencias públicas. En un primer momento, respondieron a los reiterados cuestionamientos críticos sobre la necesidad de la memoria ofreciendo una respuesta estándar acerca de la necesidad de limpiar las heridas purulentas y sanar a la nación mediante la creación de un registro histórico adecuado del

19 El siguiente material se toma de Transcripts of TRC Public Hearings, recuperado de: http:// www.trcsierraleone.org/drwebsite/publish/index.shtml (consultado en abril de 2008). 
pasado de la nación. Posteriormente, sin embargo, su tono cambió y pasó a poner menos énfasis en la necesidad de recordar (por lo menos para los individuos), y se limitó a instar a las víctimas a perdonar y reconciliarse con los perpetradores. Hacia el final de las audiencias, algunos comisionados incluso deseaban a las víctimas que tuvieran la "esperanza y el coraje para seguir adelante y olvidar el pasado", o afirmaban directamente que la Comisión de hecho les solicitaba que "perdonasen y olvidasen". En repetidas ocasiones se afirma que lo más importante es el progreso de la nación: "todo lo que queremos es la reconciliación para que el pasado sigua siendo el pasado, y todos sean capaces de trabajar hacia el progreso y el desarrollo".

\section{El discurso histórico moderno, el proyecto de la simultaneidad y la producción de "distancia"}

¿Qué ha sucedido con mi afirmación de que el campo de la justicia transicional es el escenario de lucha entre políticas del tiempo opuestas, y que las comisiones de la verdad recurren a la "historia" principalmente con el fin de apaciguar la fuerza problemática de la "memoria"?

Hemos aprendido de Benedict Anderson (2006) que la "oscura génesis" de las naciones modernas como "comunidades imaginadas" no puede comprenderse sin considerar el desarrollo de una noción específica de simultaneidad. Esta "simultaneidad transversal" que se mide por el reloj y el calendario lleva un largo tiempo de construcción y, según Anderson, está en marcado contraste con la concepción cristiana medieval de "simultaneidad a lo largo del tiempo", en la que el pasado y el futuro se fundían en un presente instantáneo por medio de la prefiguración y realización divina. La idea de la nación moderna como una comunidad sólida que se mueve a través de la historia es un análogo exacto de la idea de un "organismo sociológico que se mueve calendáricamente a través de un tiempo homogéneo y vacío". Como lo expresa Anderson:

Un americano nunca conocerá, o siquiera sabrá los nombres de más de un puñado de sus alrededor de 240.000 compañeros estadounidenses. No tiene ni idea de lo que están haciendo en ningún momento. Pero tiene plena confianza en su actividad constante, anónima y simultánea (Anderson, 2006).

La construcción de la nación podría entonces ser leída como una creación compleja y frágil de una experiencia colectiva de la simultaneidad temporal, o de la sincronía ${ }^{20}$.

20 Curiosamente, la descripción de Anderson de la estrecha relación entre la política del tiempo y el proyecto de construcción de la nación en términos de la creación de 
Sin embargo, es precisamente este proyecto de simultaneidad el que se ve amenazado por las abundantes "memorias de los ultrajes" que mantienen "vivos" los recuerdos de las atrocidades del pasado y amenazan la conciencia moderna del tiempo. El desafío planteado por esos recuerdos no es tanto que evoquen un pasado de división sino más bien, como hemos visto, que sostienen la persistencia de este pasado divisivo y lo conciben como parte constitutiva del presente. Si bien las comisiones de la verdad extraen gran parte de su legitimidad de la idea de la memoria como una forma alternativa de justicia, este particular "aguijón" -para usar una expresión de Desmond Tutu (1999, p. 271)- debe ser borrado de la memoria de los ultrajes antes de que esta pueda contribuir a la construcción de la nación. De hecho, Tutu fue un enérgico defensor de la TRC, precisamente a causa de su esperanza de abordar el problema del "extraño hábito" del pasado "de volver para acecharnos" y su negativa a "quedarse quieto y en silencio" (TRC, 1998a). Kader Asmal expresa su malestar respecto de la persistencia acechante del pasado doloroso incluso con más fuerza cuando afirma que: "No podemos simplemente descartar tales verdades diciendo que el pasado 'Ha terminado'. El pasado nunca habrá terminado a menos que avancemos de manera deliberada y sistemática para terminarlo" (Asmal, K.; Asmal, L. y Suresh Roberts, 1996, p. 161).

El terreno común que subyace a la ética de las comisiones de la verdad, como señala con razón Wole Soyinka, es la búsqueda de lo que él llama la "dicha catártica" del cierre o la búsqueda de una forma de memoria que produzca una "verdad liberadora" (1999, p. 20). El giro mundial hacia la historia en escenarios posconflicto, se puede argumentar, se debe principalmente al hecho de que muchos políticos, como señala Soyinka, se han convencido de que, si se gestiona correctamente, la memoria también es susceptible de cierre (p. 20). En este contexto, el discurso histórico moderno es útil principalmente no por su capacidad para revelar la verdad histórica, sino más bien por una propiedad que, como señala el historiador Mark Salber Phillips (2004), es muy a menudo descuidada: la de regular la "distancia" 21 . Nuestra relación con el pasado comprende la producción y manipulación de la distancia, sea acortada o ampliada. Esta distancia entre el pasado y el presente, subraya Philips, no está simplemente dada sino que se construye de forma activa en una amplia gama de "construcciones

la noción de un "mientras tanto", tiene su correlato en la tesis de Dipesh Chakrabarty sobre la relación entre un razonamiento temporal historicista y el proyecto político imperialista o colonialista de Occidente. La dominación europea del mundo en el siglo xIX, sostiene Chakrabarty, se sostenía en una teoría etapista de la historia, o lo que él llama la versión de la historia como "sala de espera", que produce la idea de un "aún no" con el fin de defender la afirmación de que un día se les permitiría a los no occidentales participar en la "modernidad política", pero que debían esperar hasta que volverse más desarrollados (2008, p. 9).

21 Me gustaría dar las gracias a Chris Lorenz por informarme sobre este artículo.

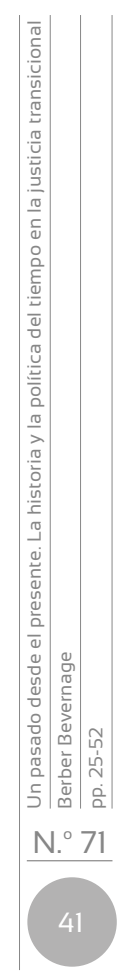


de distancia", que involucran aspectos ideológicos, implicaciones afectivas y supuestos cognitivos. Esta suposición -la de que el distanciamiento del pasado y el presente no es solo una consecuencia del paso del tiempo, sino una función de la imaginación histórica- es la base que sostiene mi propuesta central. El discurso histórico moderno, afirmo, se introduce en el lenguaje de las comisiones de la verdad sobre todo con el fin de apuntalar el proyecto nacional de simultaneidad insistiendo en la ruptura modernista entre pasado y presente. Aunque el recuerdo de un pasado de división nunca sea favorable para la creación de una experiencia nacional de simultaneidad, ayuda si ese pasado de división es recordado colectivamente de acuerdo a lo que he sugerido que son protocolos históricos modernos, es decir, permaneciendo "distante" de, o como algo separado del presente. El jurista estadounidense Bruce Ackerman subraya que las revoluciones son, ante todo, una tentativa de "cortar el tiempo en dos", separando al Antes del Ahora, y lo mismo vale para las revoluciones negociadas o los acuerdos de paz, como los de Sudáfrica o Sierra Leona (Ackerman, 1992). De manera que el giro hacia el discurso histórico moderno es parte de una política del tiempo en el que sociedades democráticas "nuevas" intentan expulsar a los fantasmas del pasado demarcando activamente aquello que pertenece a su presente histórico y aquello que no. Tanto en Sudáfrica como en Sierra Leona, por ejemplo, el perdón y la reconciliación se presentan como características que definen el presente, mientras que el rencor y la venganza son apuntados como pertenecientes al pasado ${ }^{22}$.

Se sabe muy poco sobre la eficacia global de las comisiones de la verdad y su giro hacia la historia. Sin embargo, si bien el recurso al discurso histórico moderno podría ayudar a las comisiones de la verdad a llegar al cierre que persiguen, su refuerzo de la conciencia modernista del tiempo y del proyecto de simultaneidad también puede convertir este discurso en lo que podríamos llamar una práctica "alocrónica": una práctica que (simbólicamente) asigna a otro tiempo a todos aquellos que se niegan a participar en el proceso de reconciliación o de construcción de la nación ${ }^{23}$. En la medida en que el perdón y la reconciliación se consideran

22 Sin embargo, la precisión de esta representación se puede dudar. Se ha argumentado por ejemplo que, contrariamente a la opinión establecida por la trc, la concepción de la justicia retributiva permaneció en mayor destaque en Sudáfrica que el énfasis en la reconciliación y el perdón (Wilson, 2001, pp. 25-27). Por otra parte, el académico belga Annelies Verdoolaege (2008) ha demostrado que, en las audiencias de las víctimas, los sentimientos de resentimiento, venganza y odio a menudo fueron ignorados y que los comisionados alentaron demostraciones de perdón y reconciliación.

23 El término alocronismo es tomado de Johannes Fabian (1983), quien discute este concepto principalmente en el contexto de la antropología. Según él, a menudo la antropología construye su objeto de investigación mediante la representación de la gente que estudia como si viviera en otro tiempo, más primitivo. Los antropólogos tienden a convertir la distancia geográfica en distancia temporal. A pesar de las diferencias obvias, el discurso histórico moderno comparte esta capacidad alocrónica con el discurso antropológico. 
características que definen el presente, aquellos que se niegan a perdonar o a reconciliarse no pueden considerarse plenamente simultáneos o contemporáneos con el resto de la nación, como plenos miembros de la "nueva" Sudáfrica o la "nueva" Sierra Leona. Por lo tanto, en las comisiones de la verdad existe una tendencia a identificar a los perpetradores no cooperativos y a las víctimas rencorosas como anacronismos vivientes, encerrados en el pasado y que impiden el progreso futuro de la nación.

Este mecanismo se encuentra en acción, por ejemplo, en la famosa expresión de Desmond Tutu según la cual realmente "no hay futuro sin perdón" (Tutu, 1999). La fórmula es poderosa porque acusa implícitamente a aquellos que no quieren perdonar de obstruir no solo un futuro específico, sino el futuro en general -como si estuvieran amenazando con llevar al tiempo mismo a un punto muerto-. Kader Asmal también esperaba que aquellos que veía viviendo en un mundo neurótico del olvido, olvidando tanto "tiempo" como "lugar", fueran forzados por la Comisión de la Verdad a vivir en el presente, y así llegaran a apreciar la "conciencia histórica adecuada" por la cual trabajaba la TRC. Después del estallido de la represa de la TRC, sostiene Asmal, solo los "ermitaños ahistóricos" todavía podrían negar la nueva realidad, "mirando a los fantasmas del pasado, sin darse cuenta del exorcismo que se encontraba tan decisivamente en marcha" (Asmal, K.; Asmal, L. y Suresh Roberts, 1996, p. 52). La propiedad alocrónica del discurso histórico moderno permite a Asmal plantear la siguiente pregunta retórica:

¿Exactamente dónde (y cuándo) viven esas pocas personas que todavía llevan la antigua bandera de Sudáfrica a eventos deportivos en la nueva Sudáfrica? ¿Dónde (y cuándo) viven los pilotos de nuestra línea aérea nacional, todavía ajenos al hecho de que la antigua represa $\mathrm{HF}$ Verwoerd en el centro del país, un punto de referencia que les gusta señalar a los pasajeros, ahora se llama Garieb en honor a los habitantes del área? ¿Dónde (y cuándo) viven aquellas personas que proclaman pomposamente sus derechos de propiedad sobre la tierra y el agua tomada de los negros a precios de remate después de traslados forzosos violentos? ¿En qué tiempo estamos viviendo algunos [...] ?24 (Asmal, K; Asmal, L. y Suresh Roberts, 1996, p. 209).

Con el fin de entender exactamente cómo "funciona" el discurso histórico moderno para dividir el pasado del presente y declarar pasadas las

24 Debe tenerse en cuenta, por supuesto, que Asmal está hablando aquí acerca de la conciencia histórica de una gran parte de la población de Sudáfrica y no específicamente sobre los puntos de vista de las víctimas directas o los autores materiales de las atrocidades del apartheid. El fragmento citado es relevante, sin embargo, debido a que la TRC y su discurso histórico moderno nunca fueron exclusivamente dirigidos a las víctimas directas o a los perpetradores de abusos contra los derechos humanos, sino también a la población de Sudáfrica en general. 
experiencias de las personas será útil retornar a preguntas más abstractas respecto de las relaciones entre el pasado y el presente. Según Preston King (2000), la mayoría de nuestras dificultades para comprender la idea de un pasado que continúa vivo en el presente descansan en una cierta confusión sobre lo que entendemos por presente y pasado. Con el fin de clasificar los diferentes significados que atribuimos a estas nociones correlativas pero mutuamente excluyentes, King distingue entre un "tiempo cronológico", lo que significa una secuencia temporal abstracta, y un "tiempo substantivo", que se refiere a una secuencia concreta de eventos. Basándose en el tiempo cronológico, se pueden discernir dos sentidos del presente, cada uno definido por su duración: el "presente instantáneo" y el "presente extendido". Ambos presentes se encajan entre el pasado y el futuro y tienen un carácter puramente cronológico. Pero el primero se define como el instante más pequeño posible que divide al pasado y al presente, mientras que el segundo se refiere a un periodo más prolongado (por ejemplo, un día, un año, un siglo), cuyos límites se eligen arbitrariamente, pero que otorgan al presente algún cuerpo o profundidad temporal. Debido a la falta de sentido y al carácter arbitrariamente cronológico de estos presentes y sus correspondientes pasados, los historiadores suelen utilizar un marco más sustantivo de referencia basado en criterios que no son temporales. Una de estas nociones sustantivas es la de "presente en desarrollo". Un evento seleccionado (una negociación, la depresión, la guerra, etc.) delimita un presente mientras se está desarrollando; cuando el evento se concibe como completado, el tiempo en el que se ha desarrollado se llama pasado. King señala que este es el único sentido en el que se puede decir que un pasado particular está "muerto" o "zanjado". Sin embargo, advierte de inmediato que cualquier proceso que se considera completado siempre contiene otros subprocesos que están incompletos. Por lo tanto, es muy difícil impedir que cualquier pasado efectivo sea parte del presente actualmente en desarrollo, trabaje en él o tenga influencia sobre él.

Además de los tres presentes ya descritos (instantáneo, extendido y en desarrollo), King menciona un cuarto presente, que él Ilama "presente neotérico". Trazando un paralelo con la dialéctica de la moda, señala que a menudo distinguimos entre eventos que ocurren en el presente, pero que pueden ser experimentados como "antiguos", "convencionales" o "tradicionales", respecto de aquellos que percibimos como distintivamente característicos del presente, vistos como "novedosos", "innovadores" o "modernos". Según Preston King, la periodización histórica, que aparentemente depende del presente extendido, es ante todo un ejercicio de aplicación de la dialéctica del presente neotérico. Mientras que toda noción del presente excluye su propio pasado correlativo, esto no se cumple para los sentidos no correlativos del pasado. De este modo, el presente puede ser penetrado por los sentidos no correlativos del pasado 
que se mantienen sustantivamente vivos en el presente. King explica: "El pasado no está presente. Pero ningún presente está totalmente divorciado ni carece de influencia del pasado. El pasado no está cronológicamente presente. Pero no se puede negar el hecho de que gran parte de él está sustancialmente presente" (2000, p. 55).

Al defender esta noción de la interpenetración del pasado y el presente, Preston King relativiza cualquier ruptura absoluta entre el presente y el pasado. También nos permite entender cómo el discurso histórico moderno, en el contexto de la justicia transicional, impulsa activamente la transición política hacia una nueva nación mediante la aplicación de una ruptura simbólica entre el presente y el pasado. Podríamos decir que el discurso histórico moderno recibe sus poderosas capacidades alocrónicas exorcizantes mezclando nociones sustantivas del pasado y el presente con un sentido naturalizado robustamente cronológico del tiempo. La yuxtaposición activa del presente y el pasado, lo nuevo y lo viejo, o los vivos y los muertos se encubre tras un "velo" de tiempo cronológico naturalizado. El poderoso concepto histórico del anacronismo puede utilizarse para declarar "fuera de tiempo" a determinados sujetos humanos.

Si bien el uso del discurso histórico moderno en el campo de la justicia transicional a primera vista parece estar dirigido al pasado histórico, de hecho su principal objetivo es el de inducir un presente "simultáneo" liberado de cualquier fantasma del pasado. El discurso de la historia ya "está en funcionamiento" cuando afirma que ciertos fenómenos pertenecen a su reino/objeto epistemológico: para reconocer o narrar el pasado (nacional) es central la insistencia en que ya no está presente, en que está muerto. Al declarar muerto al pasado, y diferenciarlo del presente, el discurso histórico de hecho exorciza activamente ese pasado y sus fantasmas. Esto explicaría la forma extrañamente obsesiva en que las comisiones de la verdad a menudo se refieren a las atrocidades como "los crímenes del pasado" aun cuando sucedieran recientemente y no fueran en absoluto experimentadas como parte del pasado. La descripción de estos crímenes como pertenecientes al "pasado" en un sentido cronológico acorde con el sentido común, provoca la indicación de que han "pasado" en el sentido sustancial del "pasado", "muerto" o "zanjado". Sin embargo, esto a menudo expresa más un deseo que una realidad. La performatividad del discurso histórico moderno de hecho podría ser descrita evocando la figura derridiana del forense que certifica la muerte con el fin de causarla: "declarar la muerte solo con el fin de dar la muerte" (Derrida, 1994).

Durante su periodo de trabajo activo, la TRC en Sudáfrica se ocupó también de cuestiones de cronología y periodización. Esto tenía una lógica porque la TRC, como ha subrayado un comentarista, fue la primera en construir una "nueva línea de tiempo nacional", que oficialmente reconocía y organizaba cronológicamente acontecimientos como la masacre

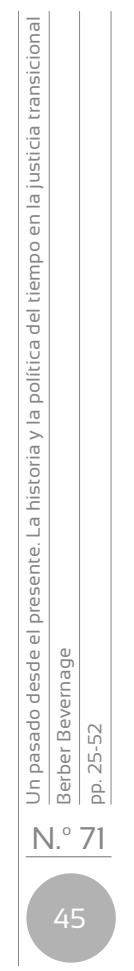


de Sharpeville, el levantamiento de Soweto, o la bomba de Church Street (Buur, 2002, p. 78). Sin embargo, el Informe final casi nunca trasciende el nivel de la cronología. Algunos de los historiadores que trabajaron en el departamento de investigación de la TRC, incluso hablaban de "una cierta obsesión de la cúpula por las cronologías", quejándose del laborioso montaje de listas que, sostenían, contribuyeron poco al desarrollo de nuevos conocimientos (Cherry, Daniel y Fullard, 2002, p. 20). En efecto, la determinación de crear una periodización rigurosa permitió a la TRC la creación de una historia de Sudáfrica en la que pasado y presente no solo fueron estrictamente separados, sino también opuestos en términos morales. Al adoptar este enfoque se tornó difícil para la TRC percibir la complejidad de las continuidades entre el pasado y el presente ${ }^{25}$.

Un último ejemplo del caso de Sierra Leona, en cambio, muestra que la cronología a veces solo desempeña un papel subsidiario en la política del tiempo. Como he mencionado, el caso de Sierra Leona es interesante porque la Comisión coexistió con un Tribunal de Guerra. Con el fin de evitar que las jurisdicciones entraran en conflicto y de crear una división del trabajo para las dos instituciones, se dispuso que el Tribunal Especial se centrara únicamente en los perpetradores con mayor responsabilidad en las atrocidades más graves, mientras que los delitos menores y crímenes cometidos por perpetradores de rango inferior o de niños soldados, se remitiría a la Comisión. Sin embargo, la división del trabajo entre la SLTRC y el Tribunal Especial se refleja también en términos de la política del tiempo. A pesar de que se esperaba que ambas instituciones investigaran periodos superpuestos, el "Acta de la Comisión de la Verdad y la Reconciliación" fue volcada en una terminología repleta de referencias al pasado y la historia (por ejemplo, el mandato de la comisión de la verdad para crear un "registro histórico imparcial", y explorar "violaciones o abusos pasados"), mientras que la redacción del texto legal que instituyó el Tribunal Especial, en cambio, no hace ninguna referencia a términos tales como historia, histórico o pasado ${ }^{26}$. De esta manera, atrocidades que se cometieron en la misma fecha cronológica podrían considerarse presentes o pasadas $-y$, respectivamente, ser castigadas o simplemente añadidas al "registro histórico imparcial"- en función de la gravedad del delito o del grado de responsabilidad del perpetrador.

25 Este mecanismo ciertamente no se limita exclusivamente a la narrativa de la TRC, sino que parece haberse convertido en una forma generalizada de tratar con el pasado del apartheid en Sudáfrica. Chana Teeger y Vered Vinitzky-Seroussi (2007) han argumentado que el Museo del Apartheid de Sudáfrica -el primer museo dedicado enteramente a contar la historia del apartheid-intenta crear una conmemoración consensual divorciando de manera consistente el (horrible) pasado del (esperanzado) presente y resistiendo líneas narrativas que ponen de relieve la importancia del pasado para cuestiones y debates presentes.

26 La jurisdicción de la sltrc se limitó al periodo entre 1991 y 1999. La de la Corte Especial, por razones principalmente pragmáticas solo comienza en 1996 y, como dato revelador, no incluye fecha de fin. 


\section{Conclusión: Nosotros las víctimas y sobrevivientes declaramos que el pasado está en el presente}

La historiografía moderna, dice el cliché, existe por la gracia del tiempo y la distancia temporal: como señala Michel de Certeau (1988), tiene lo perecedero como objeto y el progreso como lema. Como hemos visto, la génesis de la historia como disciplina académica se ha sustentado en el desarrollo de un concepto de tiempo distintivamente modernista (y occidental). Dependiente de una creencia ahora moribunda, pero una vez potente, en el progreso, y una visión del mundo convencida del poder de cambio histórico, la historiografía profesional sobre todo se ha preocupado por la ausencia, la pérdida y la conservación escrupulosa de un pasado siempre "efímero" 27.

Aquí, sin embargo, no me he ocupado de la historiografía profesional, sino con la suerte del discurso histórico moderno en el contexto de las comisiones de la verdad, en las que la causa de mayor preocupación no es la ausencia del pasado, sino su persistencia. La función simbólica de las comisiones de la verdad puede compararse con el establecimiento de una nueva constitución que instala una nueva identidad nacional. Como un complemento importante de muchas otras fuerzas que activamente crean transiciones políticas, la tarea de las comisiones de la verdad ante todo debe ser interpretada como la de un "acto constituyente" (Schaap, 2003), o una "acción fundacional" (Du Toit, 2005). La función política de la comisión de la verdad se dirige en primer lugar a la gestión de una ruptura con el pasado.

Las comisiones de la verdad emplean el discurso histórico moderno con el fin de restaurar el régimen moderno de historicidad y tranquilizar la conciencia "lábil" del tiempo de la modernidad, en la que este discurso histórico, como hemos visto, se arraiga intelectualmente. Una vez introducido en el campo de la justicia transicional, el discurso histórico tiende a entrar en conflicto con un tipo particular de memoria: la "memoria de los ultrajes". El discurso histórico moderno y las "memorias de los ultrajes" hablan al pasado con voces diferentes. La memoria de los ultrajes habla un "lenguaje de la fidelidad" 28 , negándose a dejar pasar el pasado atroz y manteniéndolo "vivo" en toda su aterradora proximidad. El discurso histórico moderno, por el contrario, habla de un "lenguaje del exorcismo", que disipa los fantasmas del pasado mediante la aplicación, o el refuerzo, de una "distancia" entre el pasado y el presente.

27 Paul Ricoeur (1988) habla de la "ontología negativa" de la historia. Paul Ricoeur, Time and Narrative, 3, Chicago, 1988, p. 147. Véase también Certeau (1973).

28 La expresión "lenguaje de la fidelidad" se utiliza en Booth (2001, pp. 777-791). 
Este mecanismo, sin embargo, no ha escapado a las críticas. En Sudáfrica, por ejemplo, las víctimas y los sobrevivientes reclaman que se les ha negado la justicia, que se rompieron las promesas de reparación y que muchos de los que desnudaron sus almas han sido relegados a los márgenes de la sociedad. Su lucha continua para ser reconocidos como ciudadanos de la nación y como parte integrante de la "nueva Sudáfri$\mathrm{Ca}^{\prime \prime}$ se puede interpretar como una crítica al funcionamiento de la TRC y, más abstractamente, de la política de tiempo que representó. El Grupo de Apoyo Khulumani -una organización que representa a alrededor de 44.000 víctimas y sobrevivientes de la violencia de la era del apartheidseñala las "asignaturas pendientes" de la TRC, y la "locura de pensar que la demanda de rendición de cuentas se desvanecerá con el tiempo". No deberían ser los perpetradores los que anuncien que ha llegado el momento de olvidar los horrores de un pasado que sigue vivo en el presen$t^{\prime}$ ", escriben. "Son las víctimas las que debería anunciar que ha llegado ese momento". Si bien apoyan los objetivos de la construcción de la nación y de la reconciliación, Ilaman a todos los ciudadanos sudafricanos a "aceptar que el pasado no ha pasado todavía", y "declarar que ese pasado está en el presente" (Khulumani Support Group, s. f.).

Mientras el distanciamiento simbólico del pasado puede ayudar a "nuevas naciones" a crear un presente simultáneo, el discurso histórico moderno tiende también a declarar fuera de ese presente a partes de la población: esto plantea la cuestión de si el recurso a la historia por parte de las comisiones de la verdad con el fin de pacificar el pasado no puede también pagar como precio a la memoria y la justicia. 


\section{Referencias bibliográficas}

Ackerman, B. (1992). The future of the liberal revolution. New Haven.

Anderson, B. (2006). Imagined communities. Londres.

Asmal, K., Asmal, L. y Suresh Roberts, R. (1996). Reconciliation Through Truth. Cape Town.

Attwood, B. (2008). In the age of testimony. Public Culture, 20 (1), 75-95, 80.

Austin, J. L. (1962). How to do things with words. Cambridge, MA.

Baets, A. de (2002). Waarheidscommissies als protohistorici. VVN-berichten, 4, 3-11.

Bevernage, B. (2008). Time, presence, and historical injustice. History and Theory, 47 (2), 149-167.

Booth, J. W. (2001). The unforgotten. American Political Science Review, 95 (4), 777-791.

Boraine, A. (2000). A country unmasked. Oxford.

Boraine, A. y Levy, J. (eds.). (1995). The healing of a nation? Cape Town.

Boraine, A.; Levy, J. y Scheffer, R. (eds.). (1997). Dealing with the past. Cape Town.

Bundy, C. (2000). The beast of the past. En J. Wilmot y L. van der Vijver (eds.). After the TRC (pp. 9-30, 20), Cape Town.

Buur, L. (2002). Monumental historical memory. En D. Posel y G. Simpson (eds.). Commissioning the past: Understanding South Africa's Truth and Reconciliation Commission (pp. 66-93). Johannesburg.

Certeau, M. de. (1973). L'Absent de l'histoire. París.

Certeau, M. de. (1988). The writing of history. Nueva York.

Chakrabarty, D. (2008). Provincializing Europe. Princeton.

Charles S. Maier. (1993). A surfeit of memory? History and Memory, 5, 1936-1951.

Cherry, J., Daniel, J. y Fullard, M. (2002). Researching the "truth". En D. Posel y G. Simpson. Commissioning the Past: Understanding South Africa's Truth and Reconciliation Commission (pp. 17-36, 20). Johannesburg.

Christie, K. y Cribb, R. (eds.). (2003). Historical injustice and democratic transition in Eastern Asia and Northern Europe: Ghosts at the table of democracy. Londres.

Cooper, T. (2005). Colonialism in question. Berkeley.

De Man, P. (1983). Literary history and literary modernity. En Blindness and Insight (p. 144). Minneapolis.

Derrida, J. (2002). Archive Fever in South Africa. En C. Hamilton et ál. (eds.), Refiguring the Archive. Cape Town. 
Derrida, J. (1994). Specters of Marx. Nueva York.

Doxtader, E. (2003). Easy to forget or never (again) hard to remember? En C. Villa-Vicencio y E. Doxtader (eds.). The Provocations of Amnesty. Claremont.

Doxtader, E. (2001). Making rhetorical history in a time of transition. Rhetoric and Public Affairs, 4 (2), 223-260.

Du Toit, A. (2005). The TRC as contemporary History. En S. Jeppie (ed.). Toward New Histories for South Africa. Lansdowne.

Dyzenhaus, D. (2000). Justifying the Truth and Reconciliation Commission. Journal of Political Philosophy, 8 (4), 470-496, 474.

Fabian, J. (1983). Time and the other. Nueva York.

Foner, E. (1995). "We Must Forget the Past". The Yale Review, 83 (2), 1-17.

Frisby, D. (1985). Fragments of Modernity. Cambridge.

Fritzsche, P. (2004). Stranded in the present. Cambridge, MA.

Grunebaum-Ralph, H. (2001). Re-Placing pasts, forgetting presents. Research in African Literatures, 32 (3), 198-212.

Gumbrecht, H. U. (2006). Presence achieved in language. History and Theory, 45 (3), 317-327.

Gutmann A. y Thompson, D. (2000). The moral foundations of truth commissions. En R. I. Rotberg y D. Thompson (eds.). Truth v. justice (pp. 22-44). Princeton.

Habermas, J. (1987). Modernity's consciousness of time. En The philosophical discourse of modernity. Cambridge, MA.

Harris, V. (2002, 3 November). Truth and reconciliation. An exercise in forgetting? Recuperado de: http://www.saha.org.za/research/publications/FOIP_5_1_Harris.pdf

Hartog, F. (2003). Régimes d'Historicité. París.

Hayner, P. (2001). Unspeakable truths. Nueva York.

Hayner, P. (2007). Negotiating peace in Sierra Leone: Confronting the justice challenge [Informe para el Centro Internacional para la Justicia Transicional y el Centro para el Diálogo Humanitario). Ginebra.

Holiday, A. (2000). Forgiving and Forgetting. En S. Nuttall y C. Coetzee (eds.). Negotiating the Past (pp. 43-56). Oxford.

Humper, J. Rt. Rev. (s. f.) Address by Rt. Rev. Joseph Humper. Recuperado de: http://www.sierra-leone.org

Hunt, L. (2008). Measuring time, making history. Budapest.

Joinet, L. (1996). La cuestión de la impunidad de los autores de violaciones a los derechos humanos (civiles y políticos). Informe final de conformidad con la decisión de la Subcomisión 1996/119.

Khulumani Support Group [Cuadros y comunicados de prensa]. Recuperado de:: http://www.khulumani.net 
King, P. (2000). Thinking past a problem. Londres.

Koselleck, R. (2004). Futures past. On the semantics of historical time. Nueva York.

Koselleck, R. (2002). The practice of conceptual history. Stanford.

Kritz, N. (ed.). (1995). Transitional justice. 3 vols. Washington D. C.

Langer, L. L. (1995). Admitting the Holocaust. Nueva York.

Levi, P. (1989). The drowned and the saved. Nueva York.

Mbeki, T. (1996). Statement to the Truth and Reconciliation Commission. Recuperado de: http://www.doj.gov.za/trc/submit/anctruth.htm\#preface

Minow, M. (1998). Between vengeance and forgiveness. Boston.

O'Flaherty, M. (2004). Sierra Leone's peace process. Human Rights Quarterly, 26, 29-62, 54.

Osborne, P. (1995). The politics of time. Nueva York, XII.

Phillips, M. S. (2004). Distance and historical representation. History Workshop Journal 57 (1), 123-141.

Posel, D. (2008). History as confession. Public Culture, 20 (1), 119-141, 127. Republic of South Africa. (1993). Interim Constitution. Pretoria.

Ricoeur, P. (1988). Time and narrative. 3. Chicago.

Rousso, H. (2002). The Haunting Past, Filadelfia

Schaap, A. (2003). The time of reconciliation and the space of politics. University of Melbourne. Documento de trabajo.

Sierra Leone Truth and Reconciliation Commission. (2004). Sierra Leone Truth and Reconciliation Commission Report 3. B. Accra: Autor.

Soyinka, W. (1999). The burden of memory, the muse of forgiveness. Oxford.

Spiegel, G. (2002). Memory and History. History and Theory, 41 (2), 149-62.

(S. F.) Transcripts of TRC Public Hearings. Recuperado de: http://www.trcsierraleone.org/drwebsite/publish/index.shtml

Teeger, C. y Vinitzky-Seroussi, V. (2007). Controlling for consensus. Symbolic Interaction, 30 (1), 57-78.

Teitel, R. G. (2003). Transitional justice genealogy. Harvard Human Rights Journal, 16, 69-94.

Torpey, J. (ed.). (2003). Politics and the past. Lanham.

Torpey, J. (2006). Making whole what has been smashed. Cambridge, Mass.

Truth and Reconciliation Commission. (1998a). Truth and Reconciliation Commission Report (N. ${ }^{\circ}$ 1-116). Cape Town: Autor.

Truth and Reconciliation Commission. (1998b). Truth and Reconciliation Commission Report (N. ${ }^{\circ}$ 5-206). Cape Town: Autor.

Tutu, D. M. (1999). No future without forgiveness. Nueva York. 
Verdoolaege, A. (2008). Reconciliation discourse. The case of the Truth and Reconciliation Commission. Amsterdam.

Wilson, R. A. (2001). The politics of Truth and Reconciliation in South Africa. Legitimizing the Post-Apartheid State. Cambridge. 